\title{
Analysis of the ground vibration generated by debris flows and other torrential processes at the Rebaixader monitoring site (Central Pyrenees, Spain)
}

\author{
C. Abancó, M. Hürlimann, and J. Moya \\ Geotechnical Engineering and Geosciences Department, Technical University of Catalonia (UPC), \\ Jordi Girona 1-3 (D2),08034 Barcelona, Spain \\ Correspondence to: C. Abancó (claudia.abanco@upc.edu)
}

Received: 25 July 2013 - Published in Nat. Hazards Earth Syst. Sci. Discuss.: 30 August 2013

Revised: 8 January 2014 - Accepted: 26 February 2014 - Published: 17 April 2014

\begin{abstract}
Monitoring of debris flows using ground vibration sensors has increased in the last two decades. However, the correct interpretation of the signals still presents ambiguity. In the Rebaixader monitoring site (Central Pyrenees, Spain) two different ground vibration stations are installed. At the first station the ground velocity signal is transformed into an impulses-per-second signal (low frequency, $1 \mathrm{~Hz}$ ). The analysis of the data recorded at this station show that the shape of the impulses signal is one of the key parameters to describe the evolution of the event. At the second station the ground velocity signal is directly recorded at high frequency $(250 \mathrm{~Hz})$. The results achieved at this station show that the differences in time series and spectral analysis are helpful to describe the temporal evolution of the events. In addition, some general outcomes were obtained: the attenuation of the signal with the distance has been identified as linear to exponential; and the assembly of the geophones to the terrain has an important effect on the amplification of the signal. All these results highlight that the definition of ground vibration thresholds for debris-flow detection or warning purposes is a difficult task; and that influence of site-specific conditions is notable.
\end{abstract}

\section{Introduction}

Debris flows are one of the most hazardous geomorphologic processes. In order to improve the understanding of debrisflow mechanisms, torrents are being instrumented with an increasing variety of sensors. The data collected are not only needed to calibrate numerical models, but also to develop and adjust warning systems.
Although debris-flows monitoring has strongly improved during the last decades and several torrential catchments in the world have been instrumented with different types of sensors and techniques (Itakura et al., 2005), this is still a challenging topic in debris-flow research. Apart from debris flows, monitoring is also used for the analysis of other types of rapid mass movements like snow avalanches or rockfalls (Suriñach et al., 2005; Bessason et al., 2007; Vilajosana et al., 2008) and bedload transport in rivers and torrents (Rickenmann et al., 1998, 2012). Torrential processes, especially debris flows, generate seismic waves in the ground, originated by the collision between boulders or between boulders and the bedrock. These vibrations can be measured by several seismic and sonic devices such as geophones, seismographs or infrasounds (Itakura et al., 2005; Kogelnig et al., 2011a). Geophones are the most common seismic sensors used in debris-flow monitoring because of their robustness and low power consumption. These features make them also very suitable not only for monitoring, but also for warning purposes. All over the world, several sites have been instrumented with geophones: Illgraben in Switzerland (Hürlimann et al., 2003), Lattenbach in Austria (Kogelnig et al., 2011a), Moscardo (Arattano et al., 2012), Acquabona (Berti et al., 2000) or Gadria (Marchi et al., 2012) in Italy, Manival or Réal in France (Navratil et al., 2011), Mount St. Helens in USA (LaHusen, 2005b), Houyenshan (Chou et al., 2010), Fong-Ciou Creek or Ai-Yu-Zi Creek (Huang et al., 2007; Fang et al., 2011) in Taiwan, and Jiangjia in China (Cui et al., 2005) are some examples. 
Some analyses of geophone signals induced by debris flows have been published during the last decades (Arattano and Moia, 1999; Berti et al., 2000; Hürlimann et al., 2003; Huang et al., 2007; Chou et al., 2010; Arattano et al., 2012). All these studies have substantially increased our knowledge on the dynamic behaviour of debris flows and the ground vibration they induce. However, there are still many open questions, such as the use of the ground vibration for the definition of thresholds; in particular, because a threshold is key information not only for the detection and warning of events, but also for the distinction between different flow types (e.g. debris flows vs. debris floods).

The ground velocity signal can be recorded by two different approaches: (a) continuously (e.g. in Moscardo torrent; Arattano and Moia, 1999); and, (b) by switching from a no-event mode into an event-mode (e.g. in the Swiss torrents; Hürlimann et al., 2003). The latter approach needs the incorporation of a trigger into the recording algorithm and the correct definition of its value. Different types of triggers can be found in the literature, such as (a) level triggers: fixed value of the ground velocity (LaHusen, 2005a) or fixed values of a transformed signal (Badoux et al., 2009; Hürlimann et al., 2013); or (b) more sophisticated thresholds based on the frequency content of the signal (Bessason et al., 2007). The type of trigger applied mainly depends on the data recording system implemented at the site. Several systems are employed, including (a) analogical recording (Arattano and Moia, 1999); (b) digital sampling (Arattano, 2000; Kogelnig et al., 2011b); and, (c) transformations of ground vibration velocity signal (Navratil et al., 2011; Abancó et al., 2012).

Normally, the threshold value (level triggers) is established combining an empirical analysis of the signals of past events and expert criteria (Kurihara et al., 2007). The threshold has to be defined at each geophone, as there are several sitespecific factors that influence the vibration recorded at the seismic sensors. An accurate assessment of the threshold is of crucial importance, especially in warning systems, when the detection of events triggers some kind of alarm process, such as the closing of traffic lines or messages to the stakeholders. However, there are only very few studies dealing with the influence of the site-specific factors affecting the vibration induced by debris-flow events (Huang et al., 2007; Navratil et al., 2011).

In this paper the features of the ground vibration signals registered at two monitoring stations located in the Rebaixader monitoring site are analysed. The main difference between the two stations is the data recording system, but also some other aspects regarding the mounting and the location of the geophones. The major purpose of this work is to define the main characteristics of debris flows and other torrential processes using the seismic signal recorded at the two stations (each with a different data recording system). Other objectives are the analysis of the influence of some site-specific factors on the ground vibration signal by means of field tests and a sensibility analysis of the threshold values. The outcomes of this research improve the knowledge on some current issues (i.e. process differentiation, geophone location, recording method or threshold assessment) and should help for the set-up of future debris-flow monitoring or warning systems.

\section{Debris flow characterisation by ground vibration monitoring}

\subsection{Debris-flow features}

Debris flows are rapid landslides formed by water and solid material poorly sorted, from boulder to clay (Iverson, 1997). Pierson (1986) describes a typical debris flow in three parts: the front, the fully developed debris flow (also called "body") and the tail. The front carries the biggest boulders and is followed by the debris flow body; both of them are characterised by a high sediment concentration and a turbulent regime. At last, there is the tail with much less solid material concentration, which can also be described as a hyperconcentrated flow. Many debris-flow events occur in a series of surges, each of them showing a front, a body and a tail (Pierson, 1986; Johnson and Rodine, 1984).

The coexistence of torrential processes has been noted in the Rebaixader site. Debris floods can be defined as episodes of massive bedload transport characterised by a limited maximum grain size (Aulitzky, 1982). Debris floods are also described as very rapid surging flows of water in a steep channel heavily charged with debris (Hungr et al., 2001). A debris flood may transport quantities of sediment comparable to a debris flow, in the form of massive surges. However, the transport is carried out by the tractive forces of water overlying the debris. As a result, the peak discharge of a debris flood is comparable to that of a water flood (perhaps multiplied by a factor up to 2). This fact clearly contrasts with the peak discharges of debris flows, which are tens of times greater than major water floods (VanDine, 1985; Hungr et al., 2001). Another important difference between debris flows and debris floods is the absence of the bouldery front.

Sediment concentration and boulder content alters the energy transmitted to the ground. Thus, on one hand debris flows can be distinguished from other torrential processes and, on the other hand, the different phases of a debris flow can be detected (e.g. Huang et al., 2007; Navratil, 2013).

\subsection{Monitoring of debris-flow induced ground vibration}

Velocity of ground movement is transduced by a geophone to a voltage that is (generally linearly) related to the ground velocity. The digital measuring of the geophone output is done by sampling the signal at a fixed frequency. To avoid aliasing problems, the sampling rate must be greater than the Nyquist frequency, which is twice the highest frequency of the signal. Digital sampling is used to record the signal from the 
geophones, but other techniques based on the transformation of the original signal into simpler data have also been developed (Arattano, 2000; Navratil et al., 2011; Abancó et al., 2012). These data recording systems are widely described in the following sections.

Several features of moving debris flows have been determined due to the analyses of the ground vibrations time series. For instance, the correspondence between the flow stage and the ground velocity signal (Arattano and Moia, 1999), or the increase of the amplitude of the ground vibration as the flow front approaches to the seismic sensor (Arattano et al., 1999). Furthermore, the flow volume was correlated with the time integral of the acceleration amplitude (Suwa et al., 2000). Other authors found some general patterns in the frequency domain. For instance, LaHusen (1996) described the typical peak frequency range of the debris flows between 30 and $80 \mathrm{~Hz}$, or Huang et al. (2007) suggested this range from 50 to $100 \mathrm{~Hz}$.

\subsection{Ground vibration site-specific factors}

Both the amplitude and the frequency of the signal measured by the geophones depend on several site-specific factors (Yin et al., 2007; Navratil et al., 2013). The influencing factors considered herein are the distance between the sensor and the debris-flow path, the material in the channel and in the channel banks and the assembly of the geophone.

Geophones are generally installed outside the channel bed, in a protected location, to avoid damage when a torrential event occurs. However, waves are attenuated with the distance and they do not travel long distances (LaHusen, 2005b). For this reason, the distance between sensor and flow path is a crucial factor and geophones are commonly installed not further than a few tens of metres from the active channel or directly on its lateral banks.

The attenuation of the seismic waves depends on the properties of the material the wave travels through. Depending on the material, the absorption of the energy by the ground is higher or lower (Itakura et al., 2000; Suriñach et al., 2001; Biescas et al., 2003). Also the physical properties of the transmission medium affect the velocity of the waves. For example, $P$ wave velocity ranges from about $350 \mathrm{~m} \mathrm{~s}^{-1}$ in alluvium up to $700 \mathrm{~m} \mathrm{~s}^{-1}$ in bedrock (Arattano and Moia, 1999).

When geophones cannot be buried in soil, the sensors must be fixed to the bedrock, big boulders or existing concrete structures (e.g. check dams). In this case, the method of fixing the geophones to these hard surfaces controls the transfer of vibrations to the sensor; and, consequently, has a strong influence on the signal recorded. Since the surfaces are often irregular, different assembly systems are designed in the existing monitoring stations (Abancó et al., 2012). a)

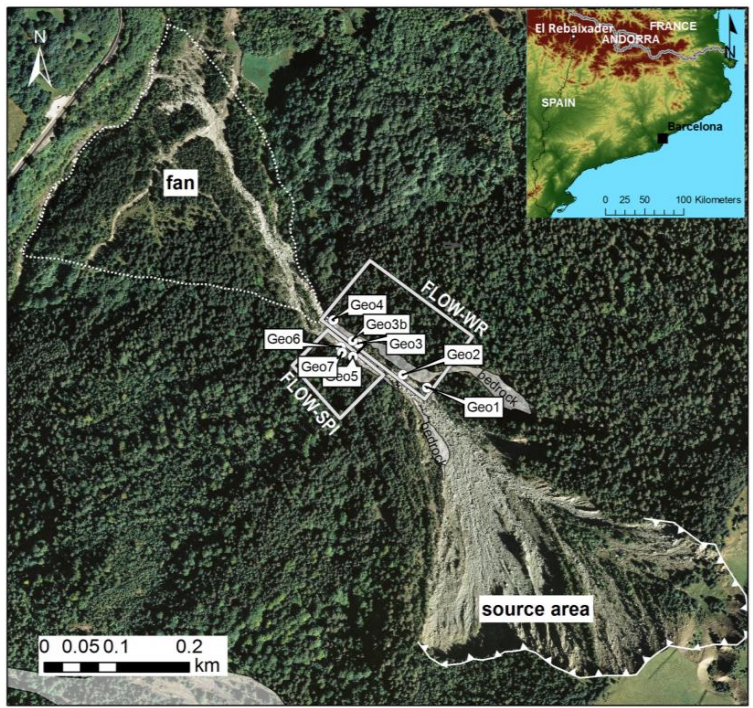

b)

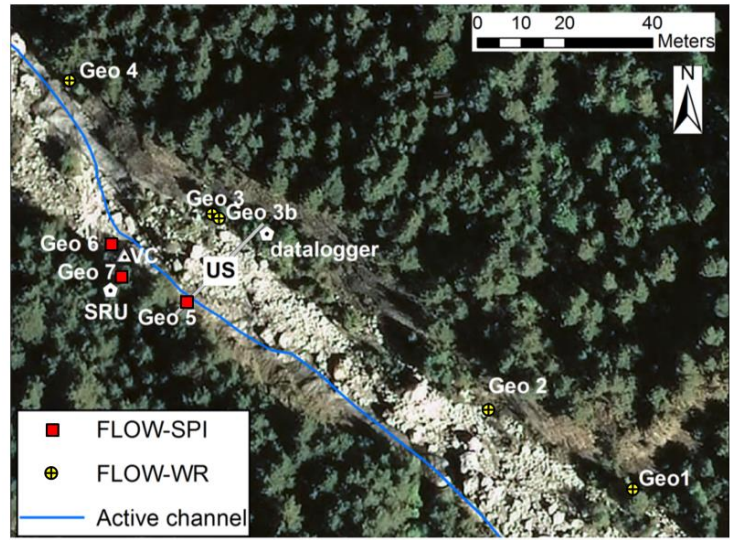

Fig. 1. (a) The Rebaixader torrent, its fan and source area. Seismic stations (FLOW-WR and FLOW-SPI) and the corresponding geophones are indicated and labelled. The ultrasonic device is represented by a black line in the middle of the channel reach. Inset shows the location of the Rebaixader site; (b) detailed location of the sensors at the channel section.

\section{Description of the Rebaixader site}

\subsection{General setting}

The Rebaixader catchment is a first-order basin with an area of $0.53 \mathrm{~km}^{2}$, which is located in the Central Pyrenees near the village of Senet (Fig. 1). The catchment has the typical morphology of a torrential basin formed by three zones (erosional source area, channel zone and fan). The source area has a steep slope (average of $29^{\circ}$, but up to $50^{\circ}$ ), an area of $0.09 \mathrm{~km}^{2}$ and it is located between 1425 and $1710 \mathrm{~m}$ a.s.l. (Fig. 1). The channel zone has an average slope of $21^{\circ}$, is $250 \mathrm{~m}$ long and about $20 \mathrm{~m}$ wide and is located between 1425 and $1350 \mathrm{~m}$ a.s.l. Downstream of the channel zone, there is a fan with an area of $0.082 \mathrm{~km}^{2}$ and a mean slope of $17^{\circ}$. The 

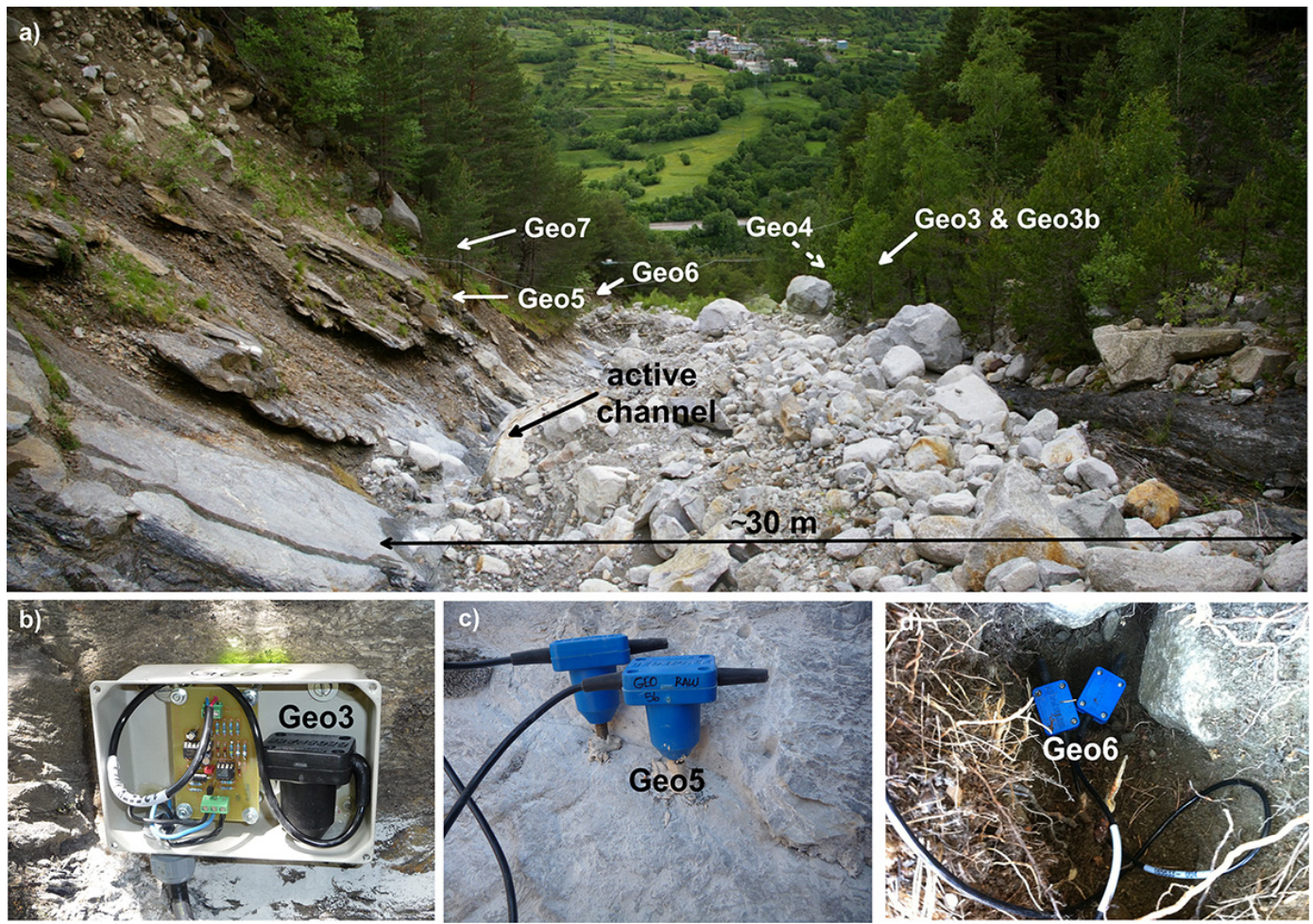

Fig. 2. (a) Downstream view inside the channel indicating the places where the geophones are placed. Pictures of the detailed assemblies are shown in (b) to (d). Picture (d) was taken during the installation of Geo6, before being covered.

Noguera Ribagorçana River defines the lower boundary of the fan. There is no protection works in the Rebaixader torrent.

The geology of the source area consists of a thick till deposit over a bedrock of slates and phyllites of Devonian age. The bedrock crops out only locally in the source and forms the margins of the channel zone. The till corresponds to a lateral moraine of the glacier that occupied the Noguera Ribargorçana Valley during the last glacial cycle (Vilaplana, 1983).

The meteorological conditions of the site are affected by the proximity of the Mediterranean Sea, the influence of the northern Atlantic winds and the orographic effects of the Pyrenees. The annual precipitation ranges from 800 to $1200 \mathrm{~mm}$. The debris flows and debris floods analysed in this study are mostly triggered by convective storms in the summer, which are characterised by short and intense rainfalls. However, it has also been observed that rainfalls of lower intensities accompanied by snowmelt can also trigger events in spring (Hürlimann et al., 2013).

\subsection{Monitoring network}

The monitoring system installed in the Rebaixader torrent includes, on one side, four stations measuring the meteorological and hydrological conditions in the catchment for the analysis of the debris-flow initiation and, on the other side, two stations regarding the detection and characterisation of the flow dynamics. Further details about the instrumentation and the events recorded can be found in Hürlimann et al. (2013). Herein, we focus on the ground vibration recorded at the two flow dynamic stations (FLOW-WR and FLOW-SPI in Fig. 1). The geophones of both stations are 1-D vertical, moving coil geophones (Geospace 20-DX) with a natural frequency of $8 \mathrm{~Hz}$ and a spurious frequency of $200 \mathrm{~Hz}$. The main difference between the stations is the data recording system. The data acquisition in station FLOW-WR is based on a low sampling rate of a transformed signal (Abancó et al., 2012), while in station FLOW-SPI the high sampling rate provides data on the original ground velocity signal.

The station FLOW-WR includes five geophones, an ultrasonic device for stage measurements and a video camera. The sampling frequency for the geophones and the ultrasonic device when an event is detected is $1 \mathrm{~Hz}$. The sensors are connected by wires and controlled by a Campbell CR1000 data logger, which is powered by a $12 \mathrm{~V} 24$ Ah battery, charged by a 30W solar panel. The data are transmitted via GSM modem to our server in Barcelona. The geophones are distributed along $175 \mathrm{~m}$ at the right side of the torrent, between 1415 and $1345 \mathrm{~m}$ a.s.l (Figs. 1 and 2a). The distances between geophones are up to $75 \mathrm{~m}$, and the distances between the sensors and the active channel range from 8 to $25 \mathrm{~m}$ (Table 1). Four of the five geophones are mounted by a metal sheet box to 
Table 1. Summary of main characteristics of the geophones analysed in this paper. IS stands for "impulses per second" and GVS stands for "ground velocity signal".

\begin{tabular}{|c|c|c|c|c|}
\hline $\begin{array}{l}\text { Geophone } \\
\text { (abbreviation) }\end{array}$ & Mounting & $\begin{array}{l}\text { Station } \\
\text { (data recording } \\
\text { system) }\end{array}$ & $\begin{array}{l}\text { Distance to active } \\
\text { channel (planimetric } \\
\text { distance in } \mathrm{m} \text { ) }\end{array}$ & $\begin{array}{l}\text { Material } \\
\text { at the } \\
\text { cross section }\end{array}$ \\
\hline Geophone 3 (Geo3) & Metal sheet box attached to bedrock & FLOW-WR (IS) & 25 & Colluvium and bedrock \\
\hline Geophone 3b (Geo3b) & Bedrock & FLOW-WR (IS) & 25 & Colluvium and bedrock \\
\hline Geophone 4 (Geo4) & Metal sheet box attached to bedrock & FLOW-WR (IS) & 8 & Bedrock \\
\hline Geophone 5 (Geo5) & Bedrock & FLOW-SPI (GVS) & 3 & Bedrock \\
\hline Geophone 6 (Geo6) & Buried into soil & FLOW-SPI (GVS) & 3 & Colluvium and bedrock \\
\hline Geophone 7 (Geo7) & Buried into soil & FLOW-SPI (GVS) & 5 & Colluvium and bedrock \\
\hline
\end{tabular}

the bedrock (geophones Geo1 to Geo4 in Fig. 2b). Each box is protected by a plastic structure in order to avoid the impact of raindrops or hail on it. The fifth geophone (Geo3b) is fixed directly on the bedrock without a metal box. It is also protected by a plastic structure like the other geophones.

The station FLOW-SPI was set up in June 2012 in order to record the ground vibration at high frequency $(250 \mathrm{~Hz})$. The station contains three geophones, which are located at the left side of the channel (Figs. 1 and 2a). The geophones are located between 3 and $5 \mathrm{~m}$ from the active channel, thus much closer than those of the station FLOW-WR (Table 1). At this station, all the geophones are fixed directly to the ground. Two of them (geophones Geo6 and Geo7) are buried in the soil (granular colluvium) at a depth of about $20 \mathrm{~cm}$ (Fig. 2d), while the third one (Geo5) is fixed to the bedrock (Fig. 2c) and protected by a plastic structure as in the FLOW-WR station. Data logging is carried out by a 24 bits broadband seismic recording unit (Spider, manufactured by WorldSensing s.l.), powered by a battery of $12 \mathrm{~V}, 22 \mathrm{Ah}$, and charged by a $50 \mathrm{~W}$ solar panel. The Spider sends the data to a gateway, where they are resent to our server via GSM modem.

\section{Analysis of transformed ground velocity signal}

\subsection{Methods}

The data recording system at the FLOW-WR station is based on the transformation of the original signal, which corresponds to a voltage signal proportional to the ground velocity, into a signal consisting of impulses per second (Abancó et al., 2012). The signal transformation is carried out by an electronic conditioning circuit board that is connected to each geophone (Fig. 2b). The aim of the transformation is twofold: (a) it filters and deletes the ground vibration noise; and, (b) the impulses per second (IS) data constitute a simple discretised signal, which can be analysed more easily and with lower memory requirements.

The signal transformation consists of two parts. First, the original voltage delivered by the geophone is filtered in order to remove low ground velocities, which are assumed to correspond to seismic noise of the site. Second, the voltage exceeding a certain threshold is transformed into an impulses signal. This filtering and transformation is made analogically by a set of electrical resistors in the conditioning circuit board, which acts like a threshold voltage. Since at Rebaixader site, two types of geophone assemblies have been applied, and two values of "ground velocity threshold" (GVth) have been defined. For the geophones mounted in a metal sheet box (Geo1, Geo2, Geo3, Geo4), the threshold corresponds to a velocity of $0.17 \mathrm{~mm} \mathrm{~s}^{-1}$. The other geophone (Geo3b), which was fixed directly to the bedrock and no resonance effect of the metal box is expected, the velocity threshold is much lower $\left(\mathrm{GVth}=0.019 \mathrm{~mm} \mathrm{~s}^{-1}\right)$. After this filtering, the signal is transformed into an impulse signal by the conditioning circuit (for further details, see Abancó et al., 2012). Finally, the signal is sent to the data logger, which counts the number of impulses each second.

The frequency of measuring is controlled by the CR1000 data logger, which was programmed to scan the geophones of the station every second. To avoid high power consumption and to optimise the memory management of the data files, an algorithm was introduced into the CR1000 data logger and the recording is not carried out continuously, but only when the number of impulses per second exceeds a threshold. This threshold is called "event mode threshold" and is based on the number of impulses per second cumulated during a certain time span (Fig. 3). Therefore, this "event mode threshold" (Eth) includes two components: (a) the number of impulses of the Eth (Ethi); and, (b) the duration of the time span in which Ethi is exceeded (Ethd). The event mode threshold was defined progressively by analysing the data of the first year of the monitoring period. Since August 2010, the Ethi has been fixed at 20 impulses per second (IMP s ${ }^{-1}$ ) with the Ethd established as three consecutive seconds. When the threshold is exceeded in any of the geophones of the station, the "event mode" is triggered by the data logger code and the signal is recorded each second. Event mode is deactivated after 2 minutes, with vibration smaller than Ethi scanned in any of the geophones. The recording is also carried out during the "no event mode" to monitor the noise and the performance of the system; although at a much lower frequency (each hour). 


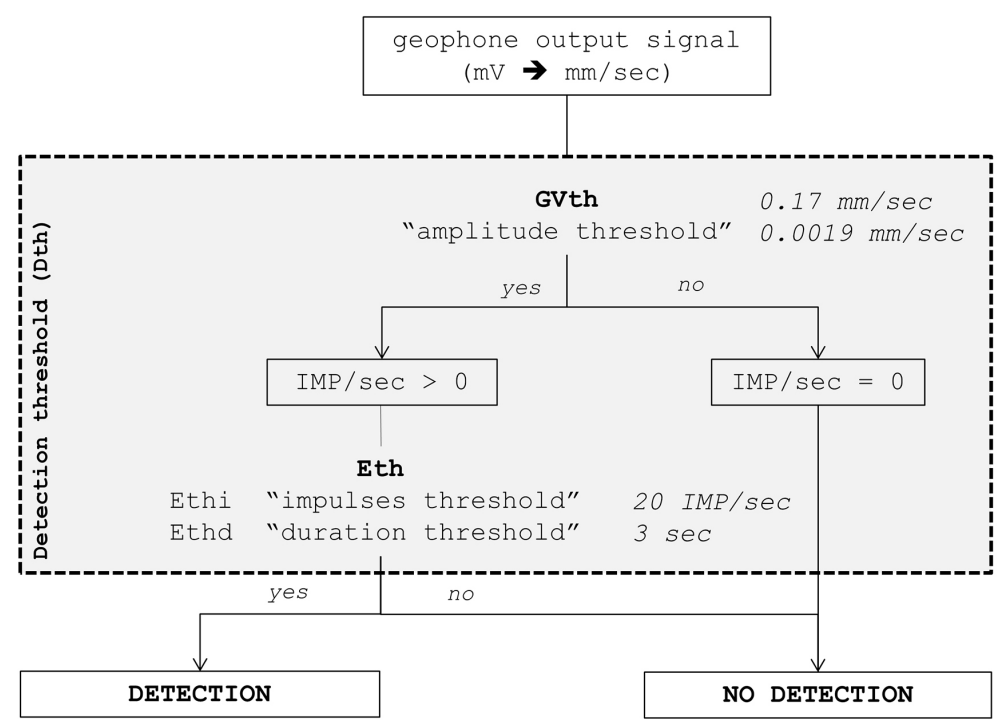

Fig. 3. Flow chart of the event detection of FLOW-WR system in the Rebaixader. In italics, the value of the parameters used nowadays in the Rebaixader.
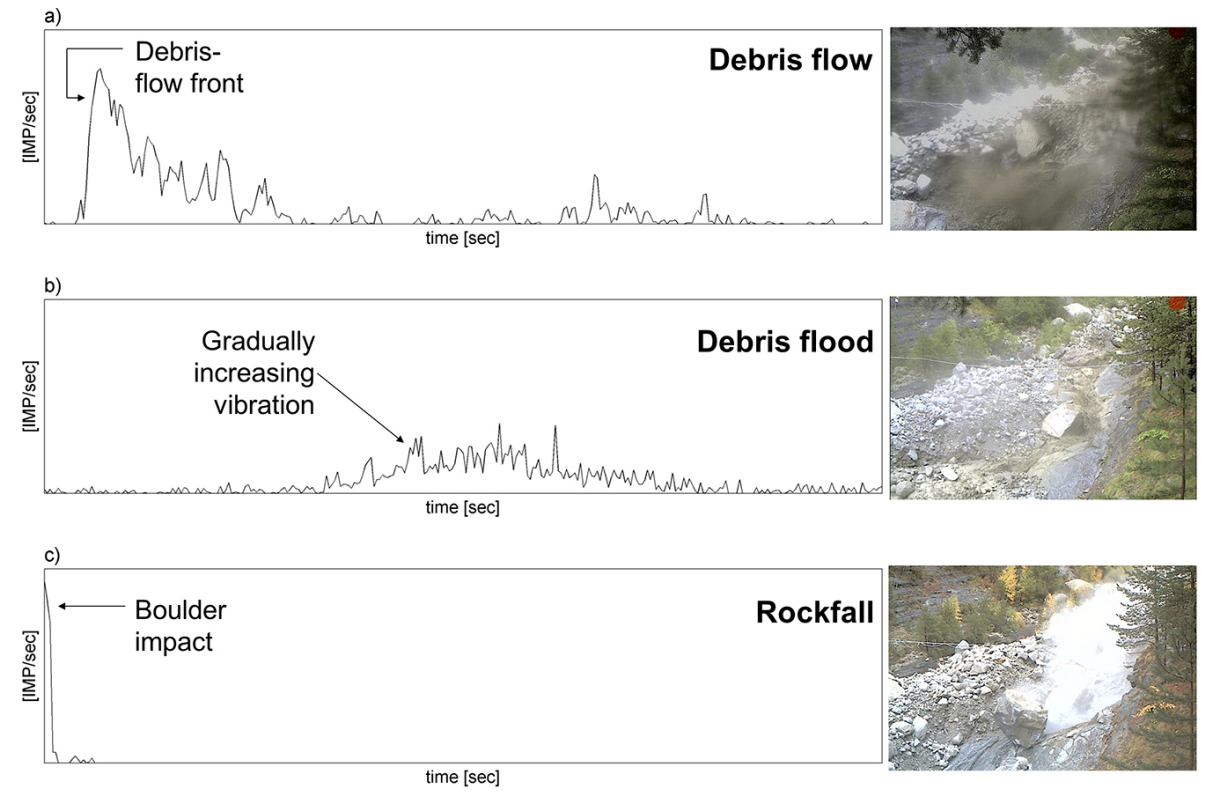

Fig. 4. Typical shapes of the IS signal registered during a debris flow (a), debris flood (b), and rockfall (c). Horizontal and vertical scales are the same in the three cases. For each process, a snapshot from the video camera is shown.

As it is shown below, several types of events (debris flows, debris floods and rockfalls) were recorded in the Rebaixader torrent. The analysis of the IS times series revealed different types of responses (IS curve morphologies). Finally, these IS curve morphologies were assigned to different types of torrential processes by means of cross-checking the vibration gathered in the five geophones, the flow depth measured by the ultrasonic device, the video images (available only for 10 events) and periodic field trips (31 campaigns) carried out after most of the events to identify geomorphic changes in the torrent.

\subsection{Results}

For the whole monitoring period, 21 torrential events have been recorded by the station since its installation in summer 2009: 6 debris flows, 11 debris floods and 4 rockfalls. Regarding the shape of the IS time series curves, three types of curves were distinguished (Fig. 4). 
A Type A curve is characterised by three phases (Fig. 4a): (a) a first phase of stationary level of no or very low IS values, (b) an abrupt increase of the impulses, reaching values over $100 \mathrm{IMP} \mathrm{s}^{-1}$ in less than $5 \mathrm{~s}$, followed by (c) a slow (mostly exponential) decrease.

A Type B curve consists of a first phase of gradual increase of IS-values, which is followed by a gradual decrease (Fig. 4b).

A Type $\mathrm{C}$ curve is defined by a very short duration ( 2 to $5 \mathrm{~s}$ fast increase of the IS-values, with a high maximum (up to $190 \mathrm{IMP} \mathrm{s}^{-1}$; Fig. 4c).

Video images and geomorphological reconnaissance clearly showed that A-curves were recorded during debrisflow events (Fig. 5b, d, f and h), the B-curves was associated with debris floods or immature phases of debris flows, and C-curves were related to rockfalls (Hürlimann et al., 2012). However, only Geo4 recorded A-curves for all the debris flows. The time series recorded at the upper geophones show B-curves, especially during the "small-magnitude" debris flows (Fig. 5a and e). These facts suggest that some debris flows may not be fully developed with a well-defined front until they reach the location of Geo4. This geophone is placed in the most downstream position (close to the fan apex) of the network. This interpretation is supported by the observations of Arattano (2003) in Moscardo, where in some events the proper debris-flow front was only visible downstream of the fan apex. In addition, it should be noted that geophones 1 to 3 are located at greater distances from the active channel (15 to $25 \mathrm{~m})$ than Geo4 $(8 \mathrm{~m})$, and that the attenuation of the vibration with distance may play a role in the recordings of debris flows, as it is shown below. Besides the shape of the curve, the peak of IMP s ${ }^{-1}$ time series at Geo4 is useful to distinguish between debris flows and debris floods. The values of peak vibration in this geophone never exceeded $100 \mathrm{IMP} \mathrm{s}^{-1}$ for debris floods, while the values are from 130 up to $211 \mathrm{IMP} \mathrm{s}^{-1}$ for debris flows. In contrast, the highest values and the shortest durations of vibration were recorded in Geo1, the uppermost geophone, and correspond to rockfalls.

Most of the recorded debris flows and debris floods present similar durations (Fig. 5), though they show a wide range of volume (Table 2). In general, these flow events last several hundreds of seconds, around $10 \mathrm{~min}$. Exceptionally, the debris-flow event registered on the 11 July 2010 lasted approximately 10 times longer. An unusually long-lasting and high-intensity rainfall event $\left(\sim 50 \mathrm{~mm} \mathrm{~h}^{-1}\right.$ as peak hourly rainfall intensity and more than $3 \mathrm{~h}$ of duration) accompanied this debris flow and generated many surges. Therefore, except for this July 2010 event, the registers suggest that there are no differences between debris flows and debris floods in terms of duration of the IS signal.
Table 2. Characteristics of the events analysed in this work. Volumes were estimated using the records gathered at the different sensors (geophones, ultrasonic device video-camera) and field observations (see Hürlimann et al., 2013 for further information).

\begin{tabular}{llr}
\hline Date $(\mathrm{dd} / \mathrm{mm} /$ yyyy $)$ & Type & Volume $\left(\mathrm{m}^{3}\right)$ \\
\hline $04 / 07 / 2012$ & Debris flow & 16200 \\
$11 / 07 / 2010$ & Debris flow & 12500 \\
$27 / 06 / 2012$ & Debris flow & 4000 \\
$05 / 08 / 2011$ & Debris flood & 2500 \\
$25 / 03 / 2010$ & Debris flow & 2100 \\
$07 / 06 / 2012$ & Debris flood & 750 \\
\hline
\end{tabular}

\section{Analysis of original ground velocity signal}

\subsection{Methods}

The station FLOW-SPI records the geophone signal directly as a voltage and represents the vertical velocity of ground vibration. The data provided by FLOW-SPI station differ from the FLOW-WR station in two main points: (a) the recording of the ground velocity signal (GVS) is continuous without distinction between "event" and "no event" modes; and (b) the signal is recorded without filtering the noise. The data are stored in "mseed" files, a typically seismological format. Each of these files contain approximately $30 \mathrm{~min}$ of data sampled at $250 \mathrm{~Hz}$ ( 250 samples per second).

The sampling frequency depends on the nature of the process and the site-specific characteristics of the geophones and their placement. Preliminary spectral analyses of some flow events in the Rebaixader catchment indicated frequency ranges between 30 and $100 \mathrm{~Hz}$. Therefore, a sampling frequency of $250 \mathrm{~Hz}$ is sufficient in our case.

FLOW-SPI station was installed in summer 2012, and for this reason only three events were recorded. Due to the small number of events, the distinction between types of events or their features by a detailed GVS analysis (as performed for the IS time series) was not possible. Video images were available only for one of the events because the first two events occurred at night and the infrared spot lights were damaged by an unexpected large debris flow. Thus, the interpretation of the GVS signals recorded during the events was carried out mainly by cross-checking the data from both stations (FLOW-WR and FLOW-SPI), by analysing the flow depth recorded at the ultrasonic device, which is located very close to the three geophones of FLOW-SPI station (Fig. 1), and by information obtained from the field reconnaissance.

\subsection{Results}

The GVS recorded during the events shows differences in amplitude and frequency according to the progression of the flowing mass over time. In Fig. 6, data from geophone Geo5 is shown for the three different events: (a) debris flow 

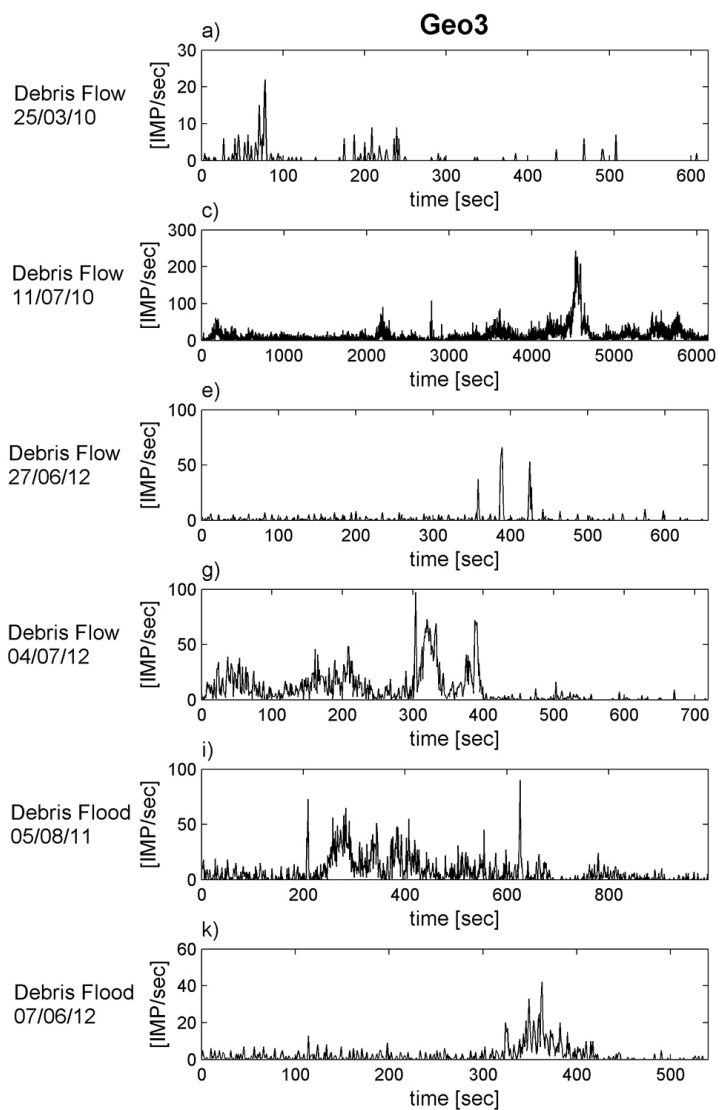
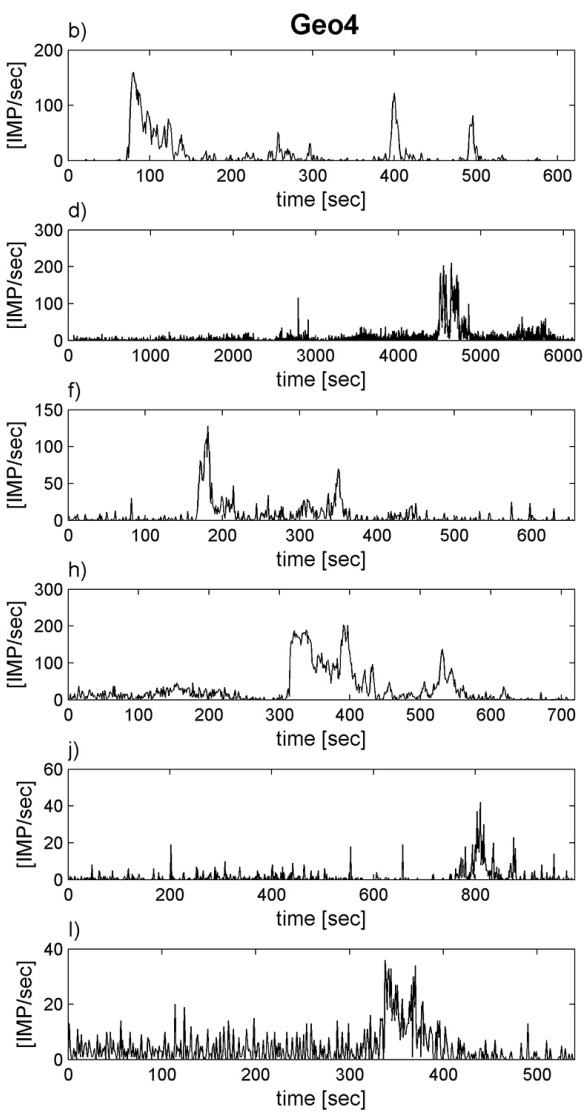

Fig. 5. Plots of the ground vibration (time vs IMP s ${ }^{-1}$ ) during some debris flows and debris floods occurred in the Rebaixader monitoring site. Left column (a, c, e, $\mathbf{g}, \mathbf{i}, \mathbf{k})$ corresponds to Geo3 and the right column (b, d, f, h, $\mathbf{j}, \mathbf{l})$ to Geo4.

4 July 2012, (b) debris flow 27 June 2012; and (c) debris flood 5 July 2012. The spectral analysis for each event was performed over windows of $2.3 \mathrm{~min}$. This time interval was selected after evaluating different options and noticing that it was optimal for the observation of the process evolution for these events.

The evolution of the seismic signal along the duration of the events can be noticed by significant differences between the following three time windows:

1. The first window corresponds to the signal recorded before the debris-flow front arrived at Geo 5 (Fig. 6a, b) or the maximum discharge is achieved in the debris flood (Fig. 6c). Time series show constant low amplitude of the ground velocity. Any significant peaks of amplitude exceed the background noise. The spectral analysis performed over the first window (Fig. 6a1, b1 and c1) show very small energies associated to this phase.

2. When the debris-flow front reaches the location of Geo5, the amplitude of the signal strongly increases. The spectral behaviour in this second window also changes. A wider spectrum characterises this time window (Fig. 6a2 and b2). A significant increase of energy is concentrated near $40-50 \mathrm{~Hz}$. The response is similar in the phase of the debris flood, especially when the sediment concentration reaches the maximum. However, the amplitude of the time series and the spectra (Fig. 6c2) is lower than for the debris flows.

3. After the main front of the debris flow passes, the amplitude decreases again, as it does the energy. For debris flows, the power spectra show a similar pattern as in the second window, but with lower energy (Fig. 6a3 and b3). For debris floods, the spectrum is small again, as it was in the first window, indicating low energy (Fig. 6c3).

Besides the evolution of the signal over time in each time series, global differences can be observed by comparing the ground vibration data of the three different events. Fig. 6a and Fig. 6c refer to the big and small debris flows respectively. The big event (Fig. 6a) reaches amplitudes of the time series greater than $1 \mathrm{~mm} \mathrm{~s}^{-1}$ during the pass of the flow front (Fig. 6a4). In contrast, the maximum values achieved during the second (smaller) debris flow (Fig. 6b) are only up to $\sim 0.5 \mathrm{~mm} \mathrm{~s}^{-1}$ (Fig. 6b4). Although the peaks are in a similar 
a)
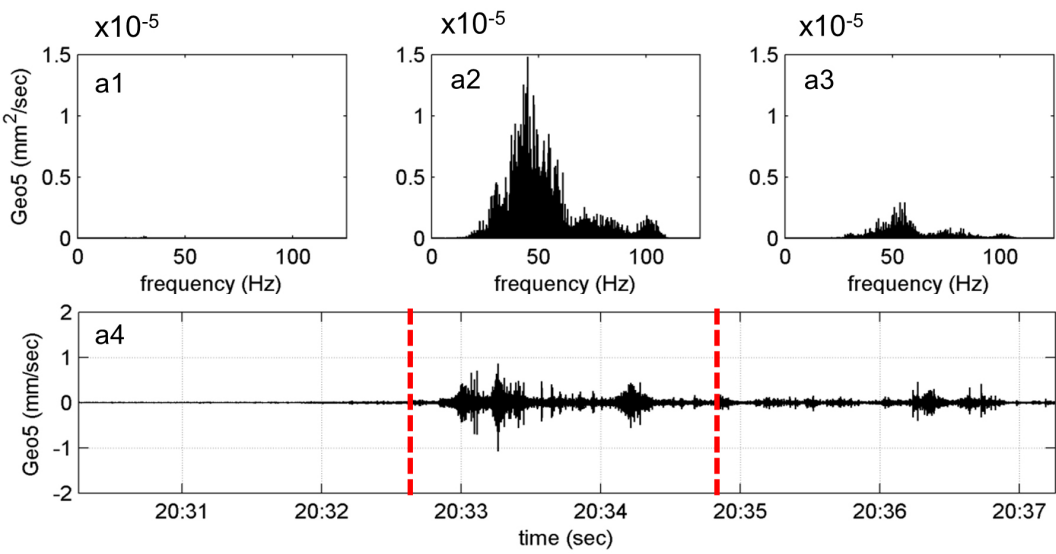

b)
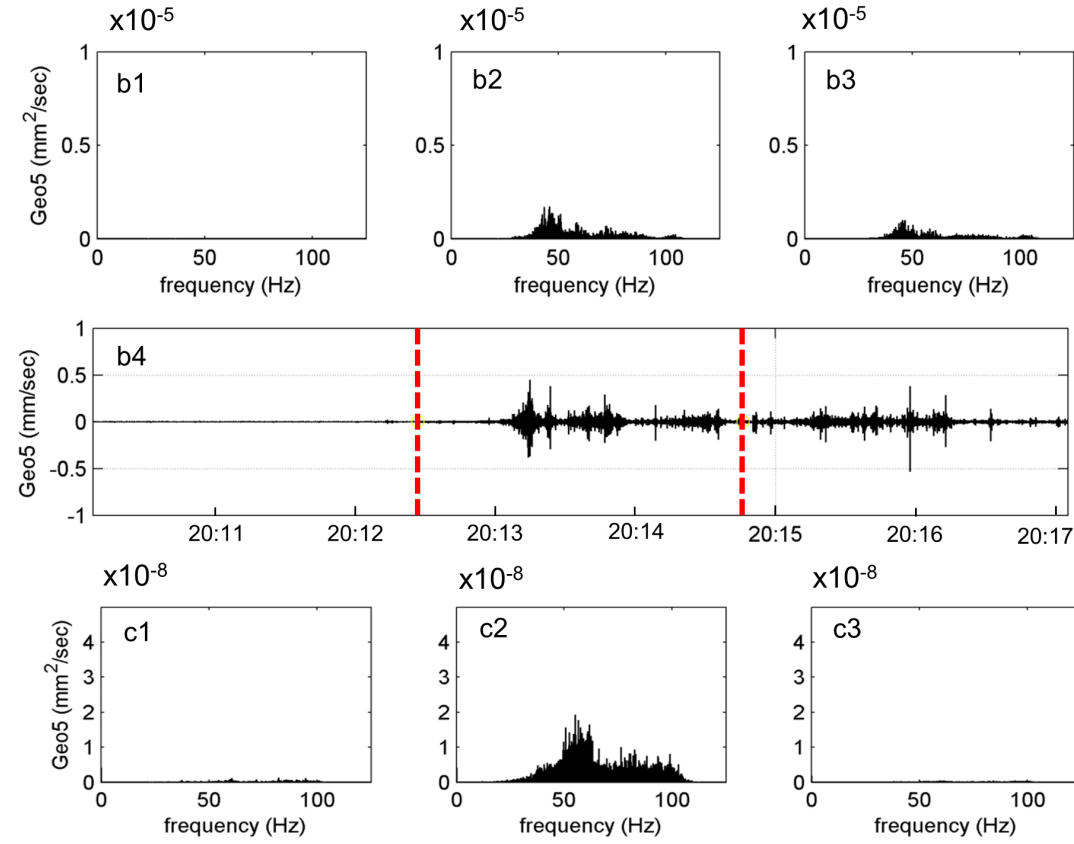

C)

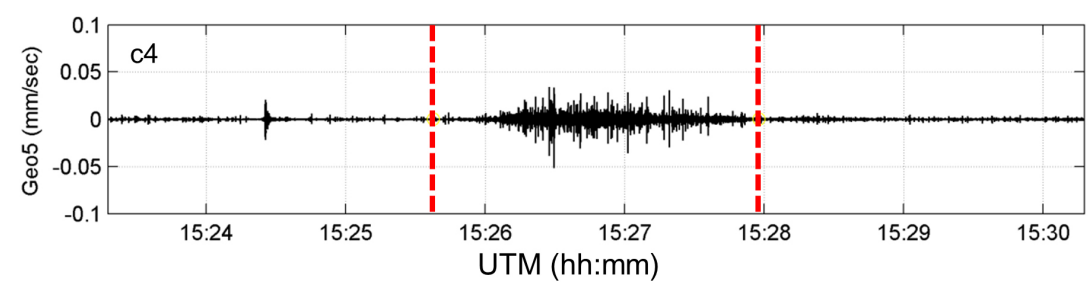

Fig. 6. Ground vibration signals from Geo5 recorded previously and during the debris flow occurred on the 4 July 2012 (a), 27 June 2012 (b) and the debris flood occurred on the 5 July 2012 (c). Time series (a4, b4 and c4) and power spectra (a1 to a3, b1 to b3 and c1 to c3) are shown respectively for the three events. Red dashed lines indicate the limits of the $2.3 \mathrm{~min}$ intervals. Each power spectra corresponds to the time interval below, respectively. Note differences in vertical scales.

frequency range $(40-50 \mathrm{~Hz})$, the energy associated is more than 7 times greater in the big event than in the smaller one. In contrast, the debris flood event achieves maximum amplitude values of $\sim 0.4 \mathrm{~mm} \mathrm{~s}^{-1}$ (Fig. 6c4). The spectrum shows a peak in $50-60 \mathrm{~Hz}$ and an energy three orders of magnitude lower than for the debris flows.

\section{Effects of site-specific factors}

The ground vibration signal detected by the geophones in both seismic stations of the Rebaixader torrent is affected by site-specific conditions of the geophones. Some factors such as the distance to the flow path, the underground material, the assembly of the geophones or the ground vibration threshold 


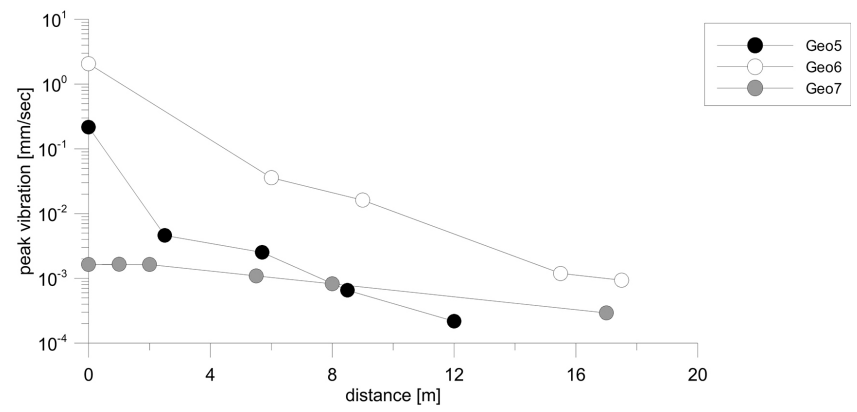

Fig. 7. Distance vs. peak of the ground vibration signals recorded during field tests. Geophones Geo6 and Geo7 are installed in colluvium and Geo5 is installed in bedrock.

used in FLOW-WR will be studied and discussed in this section.

\subsection{Underground material and distance between flow path and geophone (field tests)}

In summer 2012, we carried out some field tests at station FLOW-SPI in order to record the GVS under specific conditions. We released a $9 \mathrm{~kg}$ sledgehammer from a height of $1.5 \mathrm{~m}$ at different distances ( 0 to $20 \mathrm{~m}$ ) from the three geophones Geo5, Geo6 and Geo7 along the corresponding crosssection of the torrent. We performed the tests mostly twice to improve data quality. Similar tests have also been performed in other studies (Navratil et al., 2011; Kogelnig et al., 2011b).

The results showed that the highest amplitudes were recorded in geophone Geo6, which is buried into a thin layer $(<50 \mathrm{~cm}$ ) of colluvium (Fig. 7). Geophone Geo5 (fixed to the bedrock) shows larger amplitudes than Geo7 (buried into thicker soil layer, $>2 \mathrm{~m}$ ), however they are more than one order of magnitude lower than in Geo6. In terms of attenuation with distance, Geo5 and Geo6 show similar exponential trends, while Geo7 shows a considerably lower attenuation, following a linear trend.

The comparison of these results with the tests carried out at the Réal torrent show similarities (Navratil et al., 2011). Although at the Réal torrent the higher amplitudes were found when the geophone was fixed on a big boulder embedded in a gravel deposit (situation not present at the Rebaixader), these were followed by the geophones placed inside the soil, which is similar to Geo6. These results can be considered as experimental results that demonstrate the variations of similar signals recorded at geophones with different underground conditions. The attenuation with distance is evident and can be observed at the three geophones.

\subsection{Assembly of geophone and distance between flow path and geophone}

In order to identify the influence of the assembly of the geophone and the distance to the flow path, the signals recorded at three different geophones (Geo3, Geo3b and Geo5) were compared. These three geophones were selected, because they are installed approximately at the same cross-section of the channel (Fig. 1). Geophones Geo3 and Geo3b are located at the right side of the channel and very close together (they are only $50 \mathrm{~cm}$ apart). Geophone Geo5 is placed at the left side of the channel, $35 \mathrm{~m}$ upstream from Geo3 and Geo3b. All of them are mounted on bedrock. Geo5 and Geo3b are fixed directly on bedrock and Geo3 is mounted in a metal sheet box, which is fixed to the bedrock.

As it was mentioned above, the signal at Geo5 is recorded directly as GVS. Thus, the Geo5 data were transformed into IS in order to be comparable with the data measured at Geo3 and Geo3b, which were recorded as IS signal. This transformation was carried out as a post-process by a MATLAB code (MATLAB, 2009). The code applies the same transformations to the GVS (digitally) that is done by the signal conditioner of the FLOW-WR station (analogically). As a preliminary stage, a baseline correction was performed to avoid offsets derived from the analogue-to-digital converter (ADC). Then, the GVS below a certain threshold GVth is filtered and the GVS over the threshold is transformed into an IS signal. The GVth is applied by means of electrical resistors in the signal conditioner for Geo3 and Geo3b, but as an input variable of the MATLAB code for Geo5. The GVth values used for the transformation into IS are: $0.17 \mathrm{~mm} \mathrm{~s}^{-1}$ in Geo3 and $0.019 \mathrm{~mm} \mathrm{~s}^{-1}$ at Geo3b. The reason for choosing a 10 times higher GVth at Geo3b (fixed directly to bedrock) than at Geo3 (mounted in a metal sheet box) is given below. IS time series from Geo5 were obtained for both threshold values $\left(0.17\right.$ and $\left.0.019 \mathrm{~mm} \mathrm{~s}^{-1}\right)$. The comparison of the resulting IS time series shows the influence of the distance and the effect of the metal sheet box. In Fig. 8 the ground vibration of the 4 July 2012 debris flow is presented for the three geophones: Geo3 (Fig. 8a), Geo3b (Fig. 8c) and Geo5 (Fig. 8b and d).

The results show that the metal sheet box has a strong amplification effect on the signal. The significant difference of the records of $\mathrm{Geo} 3$ and Geo3b can only be explained by the effect of the metal sheet box, which works as a resonant structure magnifying the vibration registered by the geophone. The influence of the metal sheet box produces an increase of the values of the IS signal at Geo3, up to 10 times higher than the ones measured at Geo3b. In fact, the higher value of GVth was set for the Geo3 $\left(0.17 \mathrm{~mm} \mathrm{~s}^{-1}\right.$, instead of $0.019 \mathrm{~mm} \mathrm{~s}^{-1}$ as in Geo3b) to filter the amplification of the vibration caused by the metal box. The effect of the distance to the flow path can be noticed by comparing the data from Geo3b (Fig. 8c) and Geo5 (Fig. 8d). Both geophones are directly mounted on bedrock and the velocity threshold is the same in both cases $\left(\mathrm{GVth}=0.019 \mathrm{~mm} \mathrm{~s}^{-1}\right)$, while the distance between the geophones and the active channel is greatly different ( $25 \mathrm{~m}$ at Geo3b and $3 \mathrm{~m}$ at Geo5). The effect of the distance in Geo3b almost produces the loss of the signal, as the records do not exceed the 20 IMP s $^{-1}$. 
a)

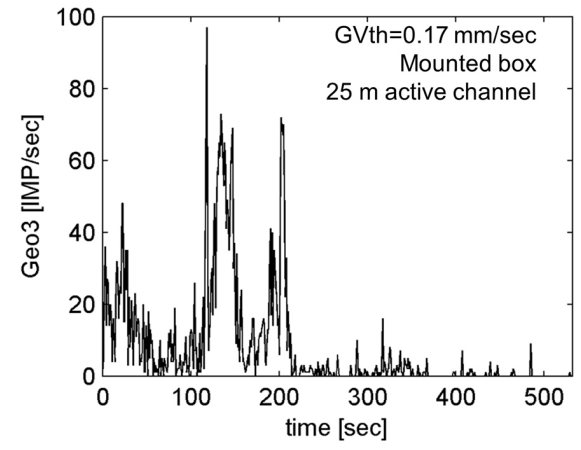

c)

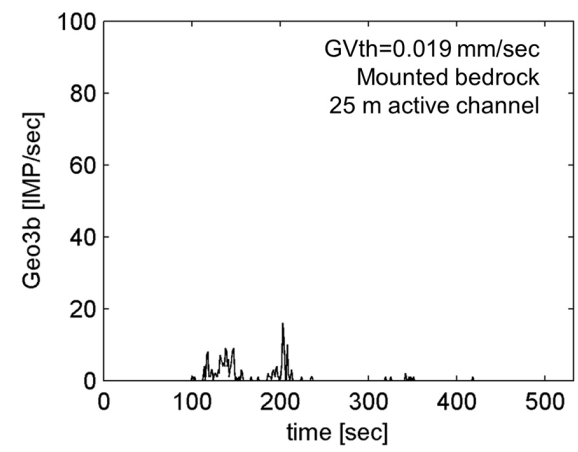

b)

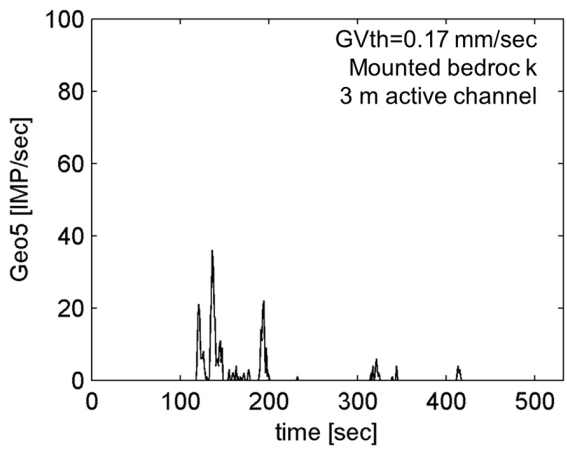

d)

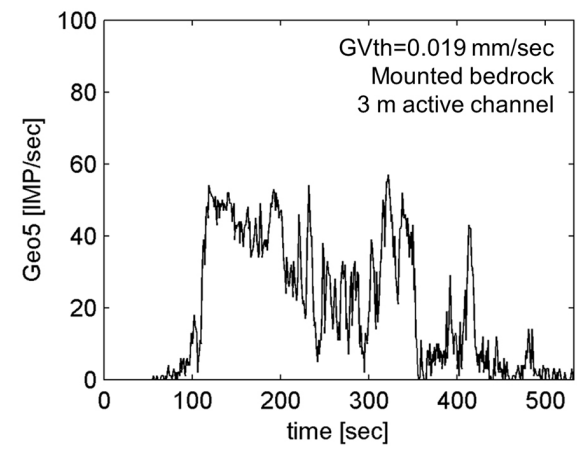

Fig. 8. Comparison of the IS signal observed during 4 July 2012 debris flow. Data registered at Geo3 (a) and Geo3b (c) and the signal obtained from the transformation of data from Geo5 into IS time series (b and $\mathbf{d}$ ).

To summarise, the influence of the box assembly and the distance greatly affect the IS signal registered at the geophones. Although an exact quantification of the effects is difficult, it can be stated that the metal sheet box amplifies the signal stronger than the attenuation caused by $20 \mathrm{~m}$ distance.

\subsection{Threshold definition for debris-flow detection}

Between August 2009 and December 2012, the "event mode" was triggered 363 times. The triggers were mostly (216 times) caused by malfunctions in one of the geophones, which was caused by a rockfall in 2010 (Hürlimann et al., 2012). Another 126 triggers were attributed to small mass movements at the lower part of the scarp area, that did not progress downstream. This hypothesis is supported by the observations obtained during the periodic field reconnaissance, which indicated no apparent geomorphic changes in the channel reach after many of these triggers. Consequently, 342 of the 363 events were not considered as significant torrential events and were classified as "other triggers", including both the malfunctions and the small movements that triggered the system. Indeed, the Eth was calibrated and adapted during the first monitoring year to minimise the recording of this type of trigger of the event mode.
The most important point regarding the development of a reliable warning system is the definition of the detection threshold, in such a way that false alarms can be reduced to a minimum. In the FLOW-WR station at the Rebaixader monitoring test site, we defined a "detection threshold" (Dth) for the monitoring system, calibrated for research purposes. The Dth is based on two thresholds: on one side the GVth, and on the other side the Eth, which is formed by Ethd and Ethi (see Sect. 4.1. and Fig. 3). As suggested by the results in previous sections, the site-specific factors influence the vibration recorded at each sensor, and the values recorded can be widely different from one geophone to another. For this reason, the values of GVth and Eth should be defined for each specific geophone, according to its placement and assembly. This calibration has a crucial importance for warning systems, but since in the Rebaixader site the installation was intended for research purposes, the thresholds have been maintained constant and low for all the geophones.

Using the data from the debris flows that occurred on 27 June 2012 and 4 July 2012, a sensibility analysis of the three Dth parameters was carried out. Different values of GVth and Eth were tested using data recorded by the geophones of FLOW-SPI station, where the complete register of the ground velocity signal was available (Geo5, Geo6, Geo7). First, the data were transformed into impulses using a MATLAB code and 10 different values of GVth. Then, two 
a)

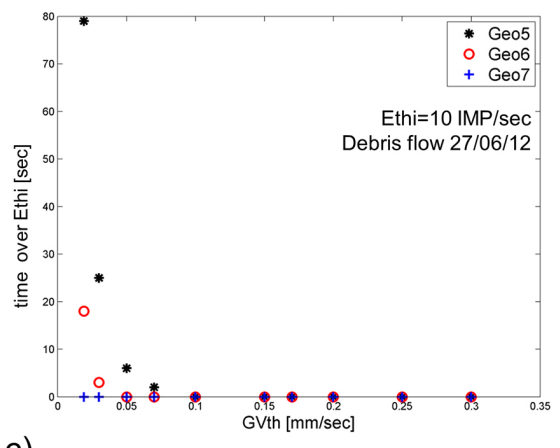

c)

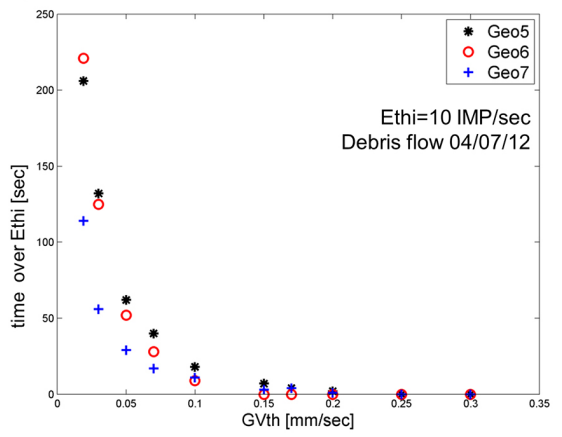

b)

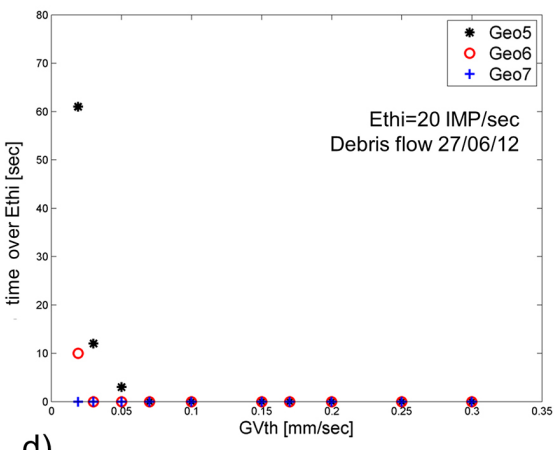

d)

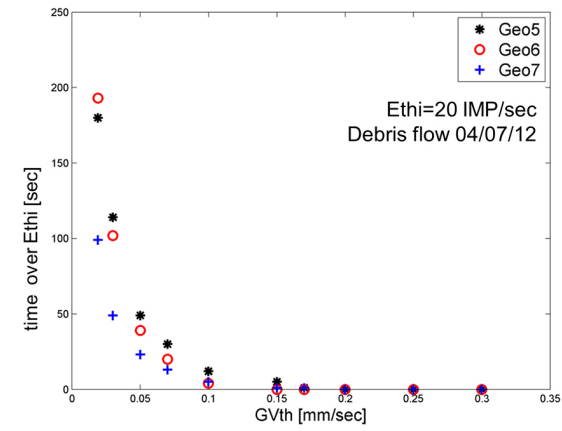

Fig. 9. Influence of the three parameters of the detection threshold (Dth): ground velocity threshold (GVth) vs. time over the IMP s ${ }^{-1}$ threshold of the event mode (Ethi). The value of the Ethi is $10 \mathrm{IMP} \mathrm{s}^{-1}$ for (a and $\mathbf{c}$ ) and $20 \mathrm{IMP} \mathrm{s}^{-1}$ for (b and d).

values of Ethi (10 and 20) were chosen and the number of seconds over it was calculated for each GVth value and Ethi. If the duration threshold Ethd is greater than the number of seconds over Ethi, no data would be recorded. Therefore the number of seconds over Ethi corresponds to the maximum value of Ethd that could be defined for each combination of Ethi and GVth in order to detect the debris flow.

The results of this analysis show two major outcomes (Fig. 9). First, the number of consecutive seconds with a GVS exceeding the Ethi exponentially decreases with increasing $\mathrm{GVth}$. This exponential decrease can be seen for both values of Ethi (10 and 20) and in both events. Second, the change of Ethi from 10 to $20 \mathrm{IMP} \mathrm{s}^{-1}$ does not influence significantly, which suggests that the most important factor for debris flow detection is the GVth.

It is worth noting that any of the debris flows would not have been detected by the Dth parameters used for most of the geophones of the station FLOW-WR $\left(\mathrm{GVth}=0.17 \mathrm{~mm} \mathrm{~s}^{-1}\right.$; Ethi $=20$; Ethd $\left.=3\right)$. This fact enforces the outcomes of the previous section on the effect of the metal sheet box, which strongly amplifies the ground vibration. Assuming a GVth - value of $0.019 \mathrm{~mm} \mathrm{~s}^{-1}$ (as used at Geo3b, where no box is added), the big event (4 July) would have been detected by the three geophones, while the small event ( 27 June) would only have been detected by Geo5 and Geo6.
In conclusion, a reliable threshold should detect the desired events as early as possible, but filter the ground velocity that does not correspond to a torrential event. The definition of an incorrect combination of the three threshold parameters (Ethd, Ethi and GVth) could suppose missing an event, such as it can be observed for the data from the event of 27 June (Fig. 9a and b), where Ethi was almost never exceeded.

Thus, we propose that best configuration at the Rebaixader site, for the detection including small events, would be a GVth from 0.1 to $0.2 \mathrm{~mm} \mathrm{~s}^{-1}$, an Ethi of 20 and an Ethd of 3 to $5 \mathrm{~s}$ for the geophones with box. For the geophones directly fixed at bedrock, the same Eth parameters and a much lower GVth are proposed. The GVth-value depends on the distance of the geophone to the active channel and should range between 0.005 and $0.03 \mathrm{~mm} \mathrm{~s}^{-1}$. For the implementation of an alarm system in the future, all these threshold values must be tested applying the following methods: (a) a calibration of the parameters in the field during a testing period of the system (including additional field tests), or (b) a detailed sensibility analysis of the three parameters applied over events recorded in FLOW-SPI and transformed into impulses using different values. However, for the second option, a greater database of events recorded in FLOW-SPI station should be available. 


\section{Conclusions}

Monitoring torrents prone to debris flows is an increasing activity all over the world. The efficiency of the geophones to monitor the occurrence of torrential processes has been widely proved, and so it is their convenience for warning purposes (Suwa and Okuda, 1985; Arattano and Moia, 1999; LaHusen, 2005b; Bessason et al., 2007; Huang et al., 2007; Badoux et al., 2009). However, there is a great variety of data recording systems, highly conditioned by the technical details of each monitoring station and many site-specific factors that affect the ground vibration measured.

In this work, two different recording systems have been compared, both of them installed in the Rebaixader torrent (Central Pyrenees). One data recording system consists of collecting the entire ground velocity signal (GVS), digitised at a high frequency rate $(250 \mathrm{~Hz})$, while the other is a simplified system, which records a transformed signal (IS) at low frequency $(1 \mathrm{~Hz})$. Both recording systems demonstrated their efficiency of recording the typical debris-flow features including the different phases of the events. Thus, both techniques should be considered as suitable for debris-flow monitoring. On the one hand, the GVS recording technique provides more information about the signal generated by the debris-flow passing, but it generates a large amount of data and subsequently consumes more electric power and time for analysis. On the other hand, the IS recording technique provides less information on the signal, but it has been demonstrated that it is reliable for detection. Moreover, it requires less power and simplifies the data collecting and gathering. These latter issues make the transformed signal especially useful for a warning system.

The data analysis showed that the differences between debris flows and debris floods can be observed by both recording techniques (GVS and IS). The differences are mainly based on the shape of the signal and the values of the ground velocity. The results point out that the geophones that better show the debris-flow features are the ones installed closest to the active channel, as can be expected. It is also worthwhile that the active channel runs over bedrock on these crosssections. The geophones located far from the active channel show less clearly the characteristics of debris flows. All these results suggest that the optimum position for a geophone to obtain reliable records of debris flows would be as closest as possible to the active channel, but in a safe position to avoid potential damage by flows, and preferably where it runs over bedrock.

The site-specific factors that influence the ground vibration measured at the geophones were evaluated by field tests and the comparison of the GVS registered at three geophones. Two major conclusions were obtained: (a) the distance produces a linear to exponential attenuation of the signal; and (b) the assembly of the geophone can strongly condition the amplification of the signal. This last conclusion was clearly observed by comparing one geophone directly fixed at bedrock with another one mounted in a metal sheet box, which is attached to the bedrock. The results suggest that the metal sheet box amplifies the signal. At Rebaixader, this amplification was useful for the detection of events, because the geophones with a metal box were not placed close to the active channel. However, another amplification system (like an electronic amplifier in the circuit board) would be more appropriate, because the exact amplification factor could be known and controlled.

Finally, the choice of a correct detection threshold (Dth) is fundamental, since it could produce the loss of an event or a great number of system triggers not related to torrential flows (which can result in false alarms in an alarm system). In this study a sensibility analysis of the parameters of the Dth was carried out. The results point out that the number of seconds over the IMP s ${ }^{-1}$ threshold (10 or $20 \mathrm{IMP} \mathrm{s}^{-1}$ ) decreases exponentially with the ground velocity threshold (GVth). From the sensibility analysis of the parameters it was noted that the ground velocity threshold GVth is the most important of the three parameters of the Dth. For the same reason, a too high value of GVth could induce a loss of an event, which would be fatal for an alarm system. In order to avoid the false alarms, the option would be to verify the propagation of the flowing mass by cross-checking different geophones.

Although many uncertainties are still remaining and additional data must be gathered and analysed, the outcomes of this research improve the knowledge on the use of seismic sensors for the detection of debris flow and other torrential processes and help on the design of an alarm system using geophones as key sensors.

Acknowledgements. This research has been funded by the Spanish Ministry MINECO contract CGL2011-23300 (project DEBRISTART). We would like to thank Ignasi Vilajosana from Worldsensing s.l., Emma Suriñach from Barcelona University and Lluís Pujades from Technical University of Catalonia for their collaboration on the geophysical analysis and interpretation. We are grateful to Massimo Arattano and Oldrich Navratil for their valuable comments and suggestions during the reviewing process, which helped to improve the manuscript.

Edited by: B. D. Malamud

Reviewed by: M. Arattano and O. Navratil

\section{References}

Abancó, C., Hürlimann, M., Fritschi, B., Graf, C., and Moya, J.: Transformation of Ground Vibration Signal for Debris-Flow Monitoring and Detection in Alarm Systems, Sensors, 12, 48704891, 2012.

Arattano, M.: On the use of seismic detectors as monitoring and warning systems for debris flows, Nat. Hazards, 20, 197-213, 2000 . 
Arattano, M.: Monitoring the presence of the debris flow front and its velocity through ground vibration detectors. Proc. 3rd International Conference on Debris-flow Hazard Mitigation: Mechanics, Prediction and Assessment, Millpress, Rotterdam, 719-730, 2003.

Arattano, M. and Moia, F.: Monitoring the propagation of a debris flow along a torrent, Hydrol. Sci. J., 44, 811-823, 1999.

Arattano, M., Marchi, L., and Cavalli, M.: Analysis of debrisflow recordings in an instrumented basin: confirmations and new findings, Nat. Hazards Earth Syst. Sci., 12, 679-686, doi:10.5194/nhess-12-679-2012, 2012.

Aulitzky, H.: Preliminary two-fold classification of torrents, Mitteilungen der Forstlichen Bundesversuchsanstalt, 243-256, 1982.

Badoux, A., Graf, C., Rhyner, J., Kuntner, R., and McArdell, B.: A debris-flow alarm system for the Alpine Illgraben catchment: design and performance, Nat. Hazards, 49, 517-539, 2009.

Berti, M., Genevois, R., La Husen, R., Simoni, A., and Tecca, P. R.: Debris flow monitoring in the Acquabona watershed on the Dolomites (Italian Alps), Phys. Chem. Earth, 25, 707-715, 2000.

Bessason, B., Eiriksson, G., Thorarinsson, O., Thorarinsson, A., and Einarsson, S.: Automatic detection of avalanches and debris flows by seismic methods, J. Glaciol., 53, 461-472, 2007.

Biescas, B., Dufour, F., Furdada, G., Khazaradze, G., and Suriñach, E.: Frequency content evolution of snow avalanche seismic signals, Surv. Geophys., 24, 447-464, 2003.

Chou, H.-T., Chang, Y.-L., and Zhang, S.-C.: Acoustic signals and geophone response induced by stony-type debris flows, Interpraevent, Taipei (Taiwan), 712-720, 2010.

Cui, P., Chen, X., Waqng, Y., Hu, K., and Li, Y.: Jiangjia Ravine debris flows in south-western China, in: Debris-flow Hazards and Related Phenomena, edited by: Jakob, M. and Hungr, O., Springer, Berlin, 565-594, 2005.

Fang, Y. M., Huang, T. M., Lee, B. J., Chou, H. T., and Yin, H. Y.: Analysis of debris flow underground sound by Wavelet Transform- A case study of events in Aiyuzih River, 5th International Conference on Debris-Flow Hazards Mitigation, Mechanics, Prediction and Assessment, Padua, 545-551, 2011.

Huang, C., Yin, H., Chen, C., Yeh, C. H., and Wang, C. L.: Ground vibrations produced by rock motions and debris flows, J. Geophys. Res., 112, F02014, doi:10.1029/2005JF000437, 2007.

Hungr, O., Evans, S. G., Bovis, M. J., and Hutchinson, J. N.: A review of the classification of landslides of the flow type, Environ. Eng. Geosci., 7, 221-238, 2001.

Hürlimann, M., Rickenmann, D., and Graf, C.: Field and monitoring data of debris-flow events in the Swiss Alps, Can. Geotech. J., 40, 161-175, 2003.

Hürlimann, M., Abancó, C., and Moya, J.: Rockfalls detached from a lateral moraine during spring season. 2010 and 2011 events observed at the Rebaixader debris-flow monitoring site (Central Pyrenees, Spain), Landslides, 3, 385-393, doi:10.1007/s10346011-0314-4, 2012.

Hürlimann, M., Abancó, C., Moya, J., and Vilajosana, I. Results and experiences gathered at the Rebaixader debris-flow monitoring site, Central Pyrenees, Spain, Landslides, doi:10.1007/s10346013-0452-y, online first, 2013.

Itakura, Y., Fujii, N., and Sawada, T.: Basic characteristics of ground vibration sensors for the detection of debris flow, Phys. Chem. Earth, Part B, 25, 717-720, 2000.
Itakura, Y., Inaba, H., and Sawada, T.: A debris-flow monitoring devices and methods bibliography, Nat. Hazards Earth Syst. Sci., 5, 971-977, doi:10.5194/nhess-5-971-2005, 2005.

Iverson, R. M.: The physics of debris flows, Rev. Geophys., 35, 245-296, 1997.

Johnson, A. M. and Rodine, J. R.: Debris flow, in: Slope Stability, edited by: D. Brunsden, and Prior, D. B., John Wiley and Sons, New York, 257-361, 1984.

Kogelnig, A., Hübl, J., Suriñach, E., Vilajosana, I., and McArdell, B.: Infrasound produced by debris flow: propagation and frequency content evolution, Nat. Hazards, 70, 1-21, doi:10.1007/s11069-011-9741-8, 2011a.

Kogelnig, A., Hübl, J., Suriñach, E., Vilajosana, I., Zhang, S., Yun, N., and McArdell, B.: A study of infrasonic signals of debris flow, 5th International Conference on Debris-Flow Hazards "Mitigation, Mechanics, Prediction and Assessment", Padua, 563-572, 2011b.

Kurihara, J., Takezawa, N., Yamakoshi, T., and Yanagimachi, T.: Study on method of setting threshold of ground vibration sensor for detecting debris flow; 4th International Conference on Debris-Flow Hazards Mitigation, edited by: Chen, C. and Major, J., Millpress, 603-611, 2007.

LaHusen, R.: Detecting debris flows using ground vibrations, 1996.

LaHusen, R.: Acoustic Flow Monitor System - User Manual, US Geological Survey, Open-File Report 02-429, 16 pp., $2005 \mathrm{a}$.

LaHusen, R.: Debris-flow instrumentation, in: Debris-flow Hazards and Related Phenomena, edited by: Jakob, M. and Hungr, O., Springer, Berlin, 291-304, 2005b.

Marchi, L., Comiti, F., Arattano, M., Cavalli, M., Macconi, P., and Penna, D.: A new debris-flow monitoring system in an Alpine catchment, Geophys. Res. Abstr., 14, EGU2012-6104, EGU General Assembly 2012, Vienna, Austria, 2012.

Navratil, O., Liébault, F., Bellot, H., Theule, J., Ravanat, X., Ousset, F., Laigle, D., Segel, V., and Fiquet, M.: Installation d'un suivi en continu des crues et laves torrentielles dans les Alpes françaises, Journée de Rencontre sur les Dangers Naturels, Lausanne, 8 pp., 2011.

Navratil, O., Liébault, F., Bellot, H., Travaglini, E., Theule, J., Chambon, G., and Laigle, D.: High-frequency monitoring of debris-flow propagation along the Réal Torrent, Southern French Prealps, Geomorphology, 201 157-171, doi:10.1016/j.geomorph.2013.06.017, 2013.

Pierson, T. C.: Flow behavior of channelized debris flows, Mount St. Helens, Washington, in: Hillslope Processes, The Binghamton symp. in geomorphology, edited by: Abraham, A. D., Allen \& Unwin, Boston, 269-296, 1986.

Rickenmann, D., D’Agostino, V., Dalla Fontana, G., Lenzi, M., and Marchi, L.: New results from sediment transport measurements in two Alpine torrents, Hydrology, Water Resources and Ecology in Headwaters, Merano (Italy), 248, 283-289, 1998.

Rickenmann, D., Turowski, J. M., Fritschi, B., Klaiber, A., and Ludwig, A.: Bedload transport measurements at the Erlenbach stream with geophones and automated basket samplers, Earth Surf. Proc. Landf., 37, 1000-1011, doi:10.1002/esp.3225, 2012.

Suriñach, E., Furdada, G., Sabot, F., Biescas, B., and Vilaplana, J. M.: On the characterization of seismic signals generated by snow avalanches for monitoring purposes, Ann. Glaciol., 32, 268-274, 2001. 
Suriñach, E., Vilajosana, I., Khazaradze, G., Biescas, B., Furdada, G., and Vilaplana, J. M.: Seismic detection and characterization of landslides and other mass movements, Nat. Hazards Earth Syst. Sci., 5, 791-798, doi:10.5194/nhess-5-791-2005, 2005.

Suwa, H. and Okuda, S.: Measurement of debris flows in Japan IV International Conference and Field Workshop on Landslides, Tokyo, 391-400, 1985.

Suwa, H., Yamakoshi, T., and Sato, K.: Relationship between debris-flow discharge and ground vibration, 2nd International Conference on Debris-Flow Hazards Mitigation, Taipei, 311$318,2000$.

VanDine, D. F.: Debris flows and debris torrents in the southern Canadian Cordillera, Can. Geotech. J., 22, 44-68, 1985.
Vilajosana, I., Suri' nach, E., Abellán, A., Khazaradze, G., Garcia, D., and Llosa, J.: Rockfall induced seismic signals: case study in Montserrat, Catalonia, Nat. Hazards Earth Syst. Sci., 8, 805-812, doi:10.5194/nhess-8-805-2008, 2008.

Vilaplana, J. M.: Quaternary Glacial Geology of Alta Ribagorça Basin (Central Southern Pyrenees), Acta Geológica Hispánica, 18, 217-233, 1983.

Yin, H. Y., Huang, C. J., Chen, C. Y., Yeh, C. H., Lee, B. J., Fang, Y. M., and Chang, Y. H.: Monitoring ground vibrations generated by debris flows, 4th Int. Conf. on Debris-Flow Hazards Mitigation, Chengdu, China, 625-633, 2007. 